\title{
Induction and Mentorship of Junior Faculty Members: A Managerial Challenge in the Institutions of Higher Education in Eritrea
}

\author{
Zecarias Zemichael Woldu* \\ Department of Psychology, College of Education \\ Eritrea Institute of Technology, Mai-Nefhi, PO box 2089, Asmara, Eritrea
}

Hongyu M, Professor and Associated Dean

School of Psychology, Central China Normal University, 152 Luoyu Avenue, Wuhan, Hubei, P.R. China 430079

\begin{abstract}
Cultivation of professionalism and dispositional values in junior faculty members in institutions of higher education (IHE) is a global challenge. Junior faculty members complain of the managerial inefficiency and lack of modeling in their career development. This paper explored how Graduate Teaching Assistants (GTAs) are inducted into the system and mentored at work in the IHE in Eritrea. It assesses the institutional significance and challenges of mentoring junior faculty members in IHE. The research was conducted in 7 IHE involving 165 participants. Quantitative and qualitative data were gathered through Likert scale questionnaire and in-depth interviews. A One-Way ANOVA was used to assess the GTAs' knowledge of assigned duties and responsibilities, access to institutional information and resources, the quality of guidance and support provided and above all the mentoring state of affairs across the colleges. Results revealed that junior faculty shoulder vital responsibilities but they receive poor induction and mentoring at individual and institutional levels. A large number of junior faculty members revealed a need of serious professional molding to effectively shoulder more responsibilities in the colleges.
\end{abstract}

Keywords: induction, mentoring, junior faculty members, Eritrea

DOI: $10.7176 / \mathrm{JEP} / 11-13-01$

Publication date:May $31^{\text {st }} 2020$

\section{Introduction}

Equity and quality of tertiary education remains one of the indispensable requisites to ensure competent and versatile manpower in the contemporary societies. However, establishing more buildings and opening new educational programs is not enough to produce skilled manpower at the tertiary level of education. The quality of the human aspect of an educational institution is the premium determinant of the success or failure of its mission. An expertise of a given subject matter is not enough for an effective and productive educational system intends to render a commendable service to the community at large. Therefore, the competence, diligence and other professional qualities of faculty members of the IHE are equally important.

Cultivation of professionalism and dispositional values of junior faculty members in HEI is a global challenge. The purpose of this research is to understand how the junior faculty members are inducted into the system and mentored at work in the IHE in Eritrea. The paper assesses the support systems available in the form of induction and mentoring to the Graduate Teaching Assistants' (GTAs) duties and responsibilities, transport communication of work related information, fair share of available resources, guidance and support provided and the mentoring state of in the IHE to professionally elevate the GTAs. GTAs are Bachelors (first degree holders) working as fulfilled instructors in the IHE. The motivation of the researcher emanates from his frequent observation of phenomena of junior faculty's grievances in the IHE. The researcher searched for the global literature about the issue and found several similar stories of junior faculty members in other universities and college and realized the issue is worth of systematic understanding.

Although induction and mentorship are inseparable elements in the continuum of professional development in organizations, in this paper induction refers to an organized way of introducing GTAs to the culture, standards and procedures of the colleges and departments and their duties, responsibilities and expectations. Whereas mentoring is a continuation of induction to further influence GTAs' professionalism in teaching, research and other activities. In a nutshell, it is coaching and leading GTAs by example.

IHE are learning centers for students and faculty members as well, particularly for junior faculty members. Workplace experiences are proven shaping tools for new staff members in IHE. The circumstance creates a practical lab of professional growth, because junior faculty are presumably engaged in teaching, research and service offering activities growing in the context of institutional support and the professional empowerment from the senior faculty members.

According to the 2010/2011 academic year statistical report of the then National Board for Higher Education 
(NBHE), the majority of the national academic faculty at the IHE in Eritrea were GTAs. The figures on the bar chart clearly demonstrate that the IHE in Eritrea have huge responsibility to mentor the GTAs to build their professional competence in order to assume more responsibilities and execute them effectively.

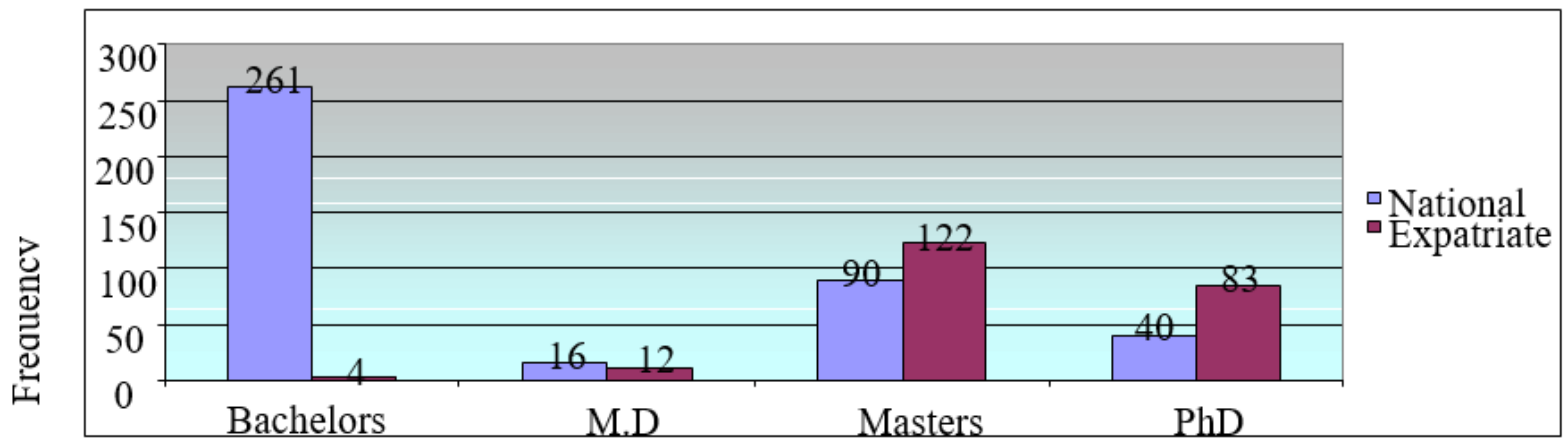

\section{Source: NBHE - Academic staff in all IHE by academic qualification - 2010/2011}

As per the African Development Fund assessment report (February, 2010), about 63\% of the "qualified" academic staff in the IHE in Eritrea are expatriates. The above statistical report of NBHE shows that $64 \%$ of the national academic staff were first degree holders (Bachelors) and $62 \%$ of the expatriates were Masters. Both reports imply the fact that the IHE have a huge task to urgently and diligently mentor the GTAs for a quality and sustainable national human resource development in the institutions.

\section{Methodology}

This research was conducted in 7 IHE in Eritrea involving 7 Deans of Colleges, randomly selected 25 senior faculty members and 133 GTAs. Qualitative and quantitative research methods were used to collect data through in-depth interviews with Deans, senior instructors and GTAs and induction-mentorship Likert scale questionnaire of 28 items distributed to GTA participants. The data collection instruments were developed in consultation with Eritrean educators and the GTAs in the IHE. The revised version of Mentoring Theory and Practice (McKimm, Jollie\& Hatter, 2007) was reviewed, but no item was adapted. The questionnaire was pilot tested and administered for the GTAs. A total of 150 questionnaires were distributed, 13 did not return and 4 were discarded. The interviews were audio recorded and carefully transcribed.

Table 1: Groups of GTAs from 7 Colleges

\begin{tabular}{llll}
\hline Group 1 & Group 2 & Group 3 & Group 4 \\
Education & Health Sciences & Arts and Social Sciences & Marine Sciences and Technology \\
Engineering & School of Medicine & Business and Economics & College of Agriculture \\
Science & & &
\end{tabular}

To compare induction and mentoring phenomena across colleges' context, 4 groups of GTAs were formed based on some elements of commonality between the services offered and some management component in the colleges. One-Way ANOVA was used to compare the qualities of induction and mentoring of the GTAs across the colleges.

\section{Induction of junior faculty members into the system of the IHE}

The human resource development mechanisms of IHE play significant strategic roles in the institutional mission achievement. During early career embark, social and professional isolations are among the major concerns for junior faculty (Johnston and Mccormack, 1997). The demanding, competitive, hectic campus life and the number of roles a faculty has to play in academics may create difficulties for junior faculty members to maintain a balance between the tasks at work and personal life affairs. Wunsch (1993) found out that setting a goal at the early stages of career planning creates a "serious planning dilemma" for junior faculty (p. 356). Hardwick (2005) remarks "It is both the best of times and the worst of times to enter an academic career" (p.22), because teaching is a demanding profession which consumes time and energy and creates discomfort, especially for new faculty to make adequate preparations at the early stages of their career (Price \& Cotten, 2006; Adams, 2002; Boyden, 2000).

The GTAs need support to cope with their personal and professional demands at the early stage of their career pursuit. In order to function as established professionals, the GTAs require access to the implicit and explicit policies, procedures, strategies and objectives of their institutions. Their knowledge, attitude, values of institutional ethos and their effectiveness can be pragmatically shaped through induction and mentoring at work. Consequently, they would be "engaged in meaningful work, connected to colleagues and common purpose, a connection to something larger than self, and it has a transcendent nature" (Kinjerski \& Skrypnek, 2006, p. 280). Professional and collegial interconnectedness facilitate the clarity of the institutional mission, teamwork spirit and effectiveness 
at individual and team level.

Induction is a good source of information for such employees to keep them on track at workplace. Provision of various channels of communication and transparent information reduces uncertainty among beginning employees (Uncertainty Reduction Theory, in Christensen, 2007). McClure (2007) notes 'Despite GTAs' sound subject knowledge, research has shown that ... it is important to provide an effective training course to adequately prepare them for the task of teaching ahead of them" (p. 656). Induction can improve the self-confidence, selfefficacy, academic skills, enthusiasm and accountability of newly hired junior faculty (Potter \& Hanratty, 2008; Major \& Dolly, 2003).

The participants revealed that the GTAs are not properly inducted into the system of the IHE. The GTAs learn the basic information regarding their duties and responsibilities as well as expectations at work informally from other colleagues in their departments, but not through formal induction. However, the findings reveal that there was statistically significant difference between the GTAs groups from different colleges with respect to their knowledge of their duties and responsibilities, $\mathrm{F}(129)=5.825 ; \mathrm{p}<0.05$ (see Table 2). Generally, GTAs complain about their access to information and resources, especially with transparent communication of information in the colleges. But a statistically significant difference was found between colleges, $F(129)=8.623 ; p<0.05$. These findings show that though GTAs complain about blurred job description and opaque institutional communication, some colleges are better at informing and inducting the GTAs at work.

Park and Ramos (2002) found very pronounced attitude differences between seniors and junior faculty with regard to the importance of induction for junior faculty members. The juniors wanted induction as a way of socialization into the culture, standards and procedures of the departments whereas the senior faculty members revealed contradicting views on the pretext delivering formal induction for junior faculty is time consuming and costly (Decker, 2008). The importance of properly inducting the junior faculty to familiarize them with their roles and job description, the institutional culture, opportunities and challenges ahead was not questionable for the current respondents irrespective of their seniority. Time and resources spent on induction can be compensated by the GTAs' efficiency at work.

Table 2: One-Way ANOVA results of GTAs' induction and mentoring

\begin{tabular}{|c|c|c|c|c|c|c|}
\hline Scales & GTA-Groups & Sum of Squares & Df & Mean Square & $\mathrm{F}$ & Sig. \\
\hline \multirow[t]{3}{*}{ Duties \& responsibilities } & Between Groups & 8.257 & 3 & 2.752 & 5.825 & .001 \\
\hline & Within Groups & 60.957 & 129 & .473 & & \\
\hline & Total & 69.215 & 132 & & & \\
\hline \multirow[t]{3}{*}{ Access to info \& resources } & Between Groups & 10.032 & 3 & 3.344 & 8.623 & .000 \\
\hline & Within Groups & 50.026 & 129 & .388 & & \\
\hline & Total & 60.058 & 132 & & & \\
\hline \multirow[t]{3}{*}{ Guidance \& Support } & Between Groups & 3.650 & 3 & 1.217 & 2.447 & .067 \\
\hline & Within Groups & 64.151 & 129 & .497 & & \\
\hline & Total & 67.801 & 132 & & & \\
\hline \multirow[t]{3}{*}{ Mentoring } & Between Groups & 1.654 & 3 & .551 & 2.500 & .062 \\
\hline & Within Groups & 28.454 & 129 & .221 & & \\
\hline & Total & 30.108 & 132 & & & \\
\hline
\end{tabular}

p is significant at 0.05 .

However, the interview participants disclosed that there is no proper induction for the GTAs. As beginning teachers these segment of academic staff in the colleges work in a "swim or sink" conditions. A GTA remarks "I could say I did not know that it was my responsibility whenever I fail to accomplish my job due to lack of clear job description" (Interview, Feb, 2011). In such situations, the lack of clarity of job description is used as an excuse for failing to do one's own duty. Integrating induction and mentoring programs as tools to socialize junior faculty members is an effective mechanism to improve work quality. Park and Ramos noted that the junior faculty members reveal:

The lack of a formal induction program leads to insufficient and inadequate briefing and preparation

for their teaching assignments, which in turn creates confusion over the role they should or might expect to play within the department. (p. 49)

In line with Park and Ramos findings, the Deans of the colleges proclaim that departments recruit the "best" graduating students based on their grade point average (GPA) to work as GTA. Thus the Deans are convinced that the recruits know everything about the system of the IHE without any additional induction programs as the result of their undergraduate experience. On the contrary, as a great player does not necessarily make a great coach, a GTA from the College of Business and Economics explained that scoring high GPA may not indicate one's pedagogical ability to convey the intended message to students as "instructor." Another participant remarked that despite the level of academic background, it is not easy to stand in front of students without the basic knowledge of pedagogy. Francis (2006) argues "whereas employers generally do a good job at welcoming and orienting the 
new starts, colleges and universities, by contrast, are generally poor at preparing students for the move" (p. 88).

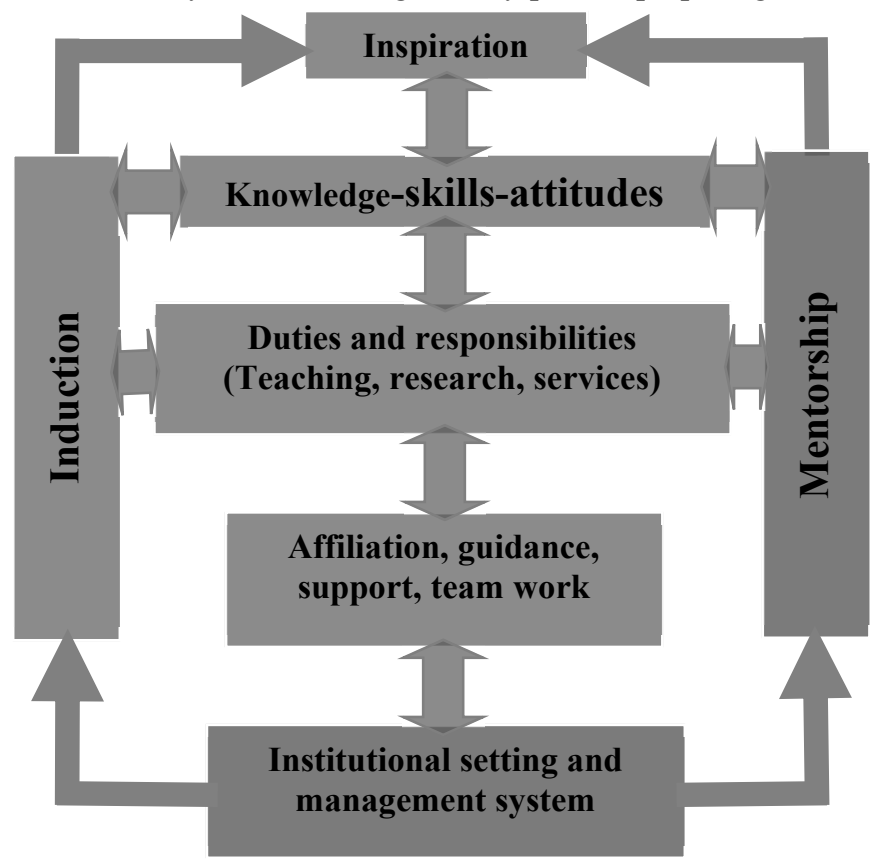

Figure 1: Multidimensional influences on junior faculty members' professional growth

Metaphorically, the figure is an induction and mentorship ladder in IHE composed of the educational institution, its management system and all the faculty members with their inputs in one way or another. The institutional setting and its management system are set up at the foundation of the ladder. This is to indicate the significance of these components to build the infrastructural capacity, design strategic programs (like induction and mentoring), create conducive teaching and learning environment, cultivate quality manpower and render competitive services based on the institutional mission and available resources.

There are no on-the-job trainings are organized to foster the GTAs' teaching and research assignments. Price and Cotten (2006) noticed that well organized on-the-job socialization for junior faculty determines the quality of their experience and the effectiveness of their contribution to the academic institutions. The GTA participants explicitly explained that things could have been much better for them and for their institutions if effective induction mechanisms were organized for them at the beginning of their career pursuit. Proper induction for new junior faculty could clarify unrealistic expectations with respect to their professional growth and facilitates institutional communication.

A senior faculty from the Eritrea Institution of Technology reflects on his early career challenges that he was given a duty to conduct practical session in a laboratory the first day recruited as GTA. There was no any precautionary advice at least on how to deal with the chemicals in the lab or some basic skills about classroom management. He elaborated that he was not trained on how to run the instruments or manage the class as a teacher. "As a beginning GTA," he says, "I suffered a lot unnecessarily though it would have been easier with the help of a senior faculty to show me the route." And he added that especially in the science areas, it is very risky for the GTAs and the students to work without induction. This is because sometimes they deal with chemicals and toxic substances like bacteria that can cause harm and even death while conducting practical sessions in labs without safety measures.

Induction and mentoring are the main arms in creating teamwork atmosphere in IHE. Inspection, recognition, motivation, feedback and other support systems are available at different parts of the ladder. The GTAs are expected to go up the ladder holding and footing on some of the stepladders at a time. Guidance and direction are needed in order to shape the GTAs' professional career and build their confidence while "climbing" up the ladder. According to Fuller and colleagues (2008), the full circle of mentoring becomes successful when the mentee becomes a mentor "to give back to the system that promoted his/her career" (p. 4). In a nutshell, the arrows symbolize the interdependence of influences within the elements of an academic institution. McKimm, Jollie \& Hatter (2007) noted that colleges and universities need to introduce change and flexibility in order to cope up with the demands of the $21^{\text {st }}$ century; otherwise they will remain marginalized despite ample educational choices and options.

\section{Mentoring situation of GTAs in the IHE}

Socialization of the GTAs is not an isolated incident, rather a continuous process. A combination of induction and 
mentoring programs plays constructive role to influence the attitude, knowledge and values of the beginning GTAs at work. Mentoring is a practice of integration that "includes the intentional process of nurturing, support, protection, guidance, instruction, and challenge ... in a developmentally appropriate timeframe" (Nickelson, 2009, p. 286; Trask, Marotz-Baden \& Settles, 2009). Ehrich, Hansford and Tennent (2001) explain that mentoring "exists within the dynamics of a professional and/or interpersonal relationship" (p. 10) as a tool of faculty empowerment and scholastic success in IHE. However, the GTAs poorly rate the quality of guidance and support they receive in the colleges from the senior faculty members and there was statistically significant difference among the GTAs of different colleges, $\mathrm{F}(129)=2.447 ; \mathrm{p}>0.05$.

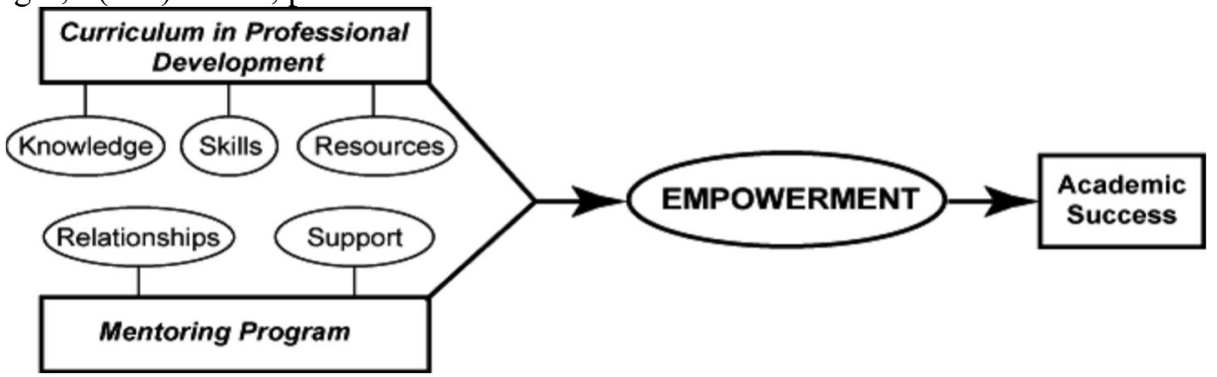

Figure 2: A model of junior faculty empowerment (adapted from Thorndyke et al., 2006)

Mentoring and engagements of the GTAs with the senior faculty can serve as a learning opportunity for staff development within the contextual reality of the institutions. GTAs want to closely work with their senior colleagues based on their areas of interest and career inclination (Price and Cotton, 2006). Tenured professors shape and influence students and junior colleagues beyond classrooms by sharing their interests and career aspirations (Petryk, 2000). The senior faculty are required of supervisory mentoring for mutual commitment with the junior faulty members. It is like "sowing the seeds of relationships, many of which flower into useful and productive mentor relationships" (Bozeman and Feeney, 2007, p.733).

The most frequently raised topics by mentoring program participants in IHE are linked to research, teaching and promotion (Kosoko-Lasaki, Sonnino, and Voytko, 2006). The interviewees unanimously appreciated the role of mentoring junior faculty to ensure quality teaching and research in IHE, because mentoring is transformational activity that promotes sharing of values, knowledge, experience, and other values (Bozeman and Feeney, 2007). A senior profession remarks:

GTA is a student prepared for graduate school and the only way he can develop is to be able to obtain mentorship from the senior faculty and to follow what the senior professors do in their instruction, research and presentations of seminars; otherwise, what is the essence of having him in a department. (Interview, January, 2011)

GTAs participated in this research poorly rated the quality of the informal mentoring they receive in their daily interaction in the colleges (Table 2). The junior faculty members do not appreciate the professional escorting expected from the senior faculty within their institutional context.

Table 2: GTAs' responses to the informal mentoring quality in the IHE

\begin{tabular}{lcccc}
\hline & \multicolumn{2}{c}{ Responses } \\
\cline { 2 - 5 } Items & $\begin{array}{c}\text { Strongly } \\
\text { disagree }\end{array}$ & Disagree & \multicolumn{2}{c}{$\begin{array}{c}\text { Strongly } \\
\text { Agree }\end{array}$} \\
\hline A senior staff regularly supervises my progress & 70 & 57 & 3 & 3 \\
The seniors lead the GTAs by example & 40 & 70 & 21 & 2 \\
I am mentored by the seniors on professional ethics & 41 & 57 & 32 & 3 \\
I am mentored by the senior faculty on research skill & 50 & 61 & 18 & 4 \\
Junior faculty mentoring is flourishing in the colleges & 59 & 54 & 20 & 0 \\
\hline
\end{tabular}

$N=133 \&$ the neutral option in the middle was deliberately omitted after pilot testing the questionnaire.

The mean scores of GTAs' mentoring quality in different colleges were computed. There was no statistically significant difference between the means of GTAs' mentoring quality across the colleges. The One-Way-ANOVA results show $F(129)=2.500 ; p>0.05$. The IHE are not positively impacting the GTAs leading them by example to follow the footsteps of the senior faculty members and to go beyond. These shortcomings might encourage junior faculty members to change their career plans at a time when it is not easy for the institutions to deal with such attrition.

The fostering value of mentoring in teaching had drawn a strategic attention in the NBHE, Eritrea. The scholarship guidelines document of the NBHE (January, 2010) states all GTAs "have to be [affiliated] to senior faculty members" (p. 2) for mentoring purpose. The affiliation procedure was projected to be based on the GTAs' area of interest. The participants expressed positive attitude towards the notion of such affiliation, but complained that it remained at a conceptual level on paper. Participants articulated that the affiliation procedure of the NBHE 
was not successfully implemented mainly due to lack of a feasibility study, lack of coordination and follow-up in the process and identification of the potential resistance from the senior faculty.

The readiness of the senior faculty members and GTAs is a main factor for the success of mentoring programs in IHE. One of the Deans from Eritrea Institute Technology tried to implement the affiliation procedures forwarded by the NBHE. He explained that the college attempted to affiliate each GTA to a senior instructor so that they attend the lectures of the respective instructors, co-teach, cooperate and learn from them. The instructors were advised to involve the GTAs in their activities and give them portions in their courses in the form of supervised teaching responsibilities. However, it was a vain effort because the affiliation led to confrontation instead of cooperation between the senior faculty members and the GTAs. Consequently, results were unsatisfactory and the Dean blames both the senior faculty and the GTAs for the failure. He indicated that some seniors lack the requisite expertise and reluctantly saying "I want to be on my own. Why team teaching? Why should I affiliate with a junior and be at a strain?"

Ehrich, Hansford and Tennent (2001) conducted meta-analytical studies of 151 and 159 mentoring articles from education and business respectively to identify positive outcomes and setbacks related to mentoring. The findings show that collegiality networking, reflection, satisfaction, interpersonal skill and personal development are the main positive outcomes for mentors in education. The researchers further revealed that lack of time, professional expertise and mismatch of personal characteristics are major problems that face mentoring relationships.

The interviewees acknowledged that most of senior faculty members themselves still need mentoring to mentor the GTAs. The participants further indicated that regardless of their academic rank, only few of the expatriate faculty had mentoring qualities. A Dean of a college noted that in some areas there are GTAs better than some high academic rank faculty and he says "One can ask who will mentor who? Otherwise, it will be a reverse mentoring" (Interview, January, 2011). Brown, Davis and McClendon (1999) advised mentoring programmers and implementers to remain vigilant to the misleading beliefs of the seemingly logical but not practical ideas like "any senior person can mentor a junior person" (p. 107). More importantly, mentoring should target the human potential development in terms of empowering individuals and improving organizational capacity.

\subsection{Institutional benefits of mentoring}

In academia, mentorship of junior faculty members is a long-term solution in the face of challenges (Carozza, 2002). Mentoring is not a panacea, but it is helpful strategy to empower and improve organizational capacity. Successful mentoring programs promote partnership and teamwork in teaching and research irrespective of gender, age, rank, and discipline in IHE (Boyden, 2000). Therefore, as an enduring relationship, mentorship is a tool to enhance career functions and a long-term investment on personal and organizational development. Mentoring has myriad personal and institutional benefits (Brown et al., 1999). Induction and mentoring of the junior faculty could result in ethically and professionally stronger, inspired faculty and a better quality of performance. The great Chinese philosopher Confucius (551-479 BCE, in Mcdevitt, 2007) appreciated the paramount role of leadership in mentoring the subordinates. Confucius further noted that junior faculty members shaped and mentored by benevolent mentors would be best suited to rule.

The GTA participants pointed out that induction is an appropriate way to clarify duties and expectations of new recruits and mentoring the junior faculty builds their self-confidence, self-efficacy and academic skills. The participants further noted that improving the enthusiasm and accountability of junior faculty at work maximizes institutional efficiency and synergy to achieve heights of excellence, boosts staff retention and quality, reduces scholarship related stress (Decker, 2008; Francis, 2006; Feiman-Nemser, 2003). It is an instrument of psychological support system, career development, symbiotic professional and social networking to address junior faculty's professional concerns and sharing of experiences. Mentoring the young staff energizes and guides their career development and creates an opportunity for them to serve as models of excellence for the undergraduate students. Brown, Davis and McClendon (1999) note:

Myriad missions exist in mentoring . . . it must be viewed as a nurturing process in which the faculty

member serves as a role model, teacher, sponsor, encourager, counselor, and friend to the students with

the end goal of promoting the latter's professional and personal development. (p. 113)

Several research findings of mentorship revealed that not only the mentees, but also the mentors get stimulation while interacting with bright and creative junior faculty members. The seniors get satisfaction from their supportive contributions, enhancing systematic and critical reflection. Moreover, the experiences ignite renewal of career ambitions for the senior faculty, enhanced status and self-esteem [seeing the fruit of their efforts] and improve their managerial skills (Kanuka, 2005). Mentoring increases the mentors' generativity, competence, technological skills and gain trusted allies. In addition, the seniors' contributions get recognition within the organization and beyond as the mentees grow professionally. Hence, mentoring process is a two way benefit, but the initiation of mentoring whether from the mentee's or mentor's interest is still contentious. 
4.2 Challenges of effective mentoring at the IHE

People learn to succeed from others in dynamic interaction (Bandura, 2001). Mentoring is a two way process that enhances stimulation on both sides. However, mentoring GTAs is not an easy task as it sounds (Waxman, Collins \& Slough, 2009), because "mentoring is very complex" business (McKimm, Jollie \& Hatter, 2007, p. 1). Mentoring "goes far beyond supervision" (Sundli, 2007, p. 205); it is a matter of "mindset" (Hardwick, 2005). Hargreaves and Fullan (2000) note "in teaching ... induction and mentoring programs have become widespread; however, their implementation has often been disappointing" (p. 50). In line with the findings of Fuller, Maniscalco-Feichtl and Droege (2008), the fact that the junior faculty members outnumber the senior faculty members is a major limitation to arrange one-to-one faculty mentoring in the IHE. This challenge is coupled with the apparent lack of coordination, associated incentives for the senior faculty members, lack of professionalism and institutional commitment.

The conventional model of formal mentoring, which requires a dyadic interaction between a mentor and mentee, is also being partly challenged because it limits the freedom of both parties to express their viewpoints by imposing "too many ... do's and don'ts" (Mason, 2005, p. 7). According to Price \& Cotten (2006), "If a formal mentoring program exists, the match is [a] hit or miss" (p. 12). The researchers noted that poor dyadic fit in formal mentoring relationships could result in more negative experiences and unwanted consequences. In the face of imbalance between senior and junior faculty, the lack of readiness of the senior faculty to coach as well as match or mismatch of personalities, junior faculty members can mentor one another or a senior faculty can guide a group of junior faculty (Adams, 2002).

\section{Conclusion}

Induction and mentoring programs are constructive ways to influence the attitude, knowledge and values of beginning faculty and to introduce them to the ethos and standards of the IHE. In academic framework, mentoring the junior faculty enhances the psychological support system, career development orientation, social networking to important figures in the institution and boosts the novice's academic self-esteem. The interviewees indicated that induction and mentoring are significantly important for beginning GTAs, but the colleges are in short supply of such support leaving the GTAs work in a "swim or sink" conditions.

The participants noted that most of the national master's holders still need mentoring to mentor the GTAs. Besides the GTAs have little expectations from the unmotivated national senior staff and majority "negligent" expatriate faculty. A visible gap was observed between theory forwarded by the NBHE and practice in the colleges; what is written in the NBHE guidelines and what is in practice at the colleges mismatch. GTAs (though bachelor holders) are teaching even senior class courses. The GTAs are known by the Deans as "the backbones" of the colleges working as instructors and even as head departments in some college. However, taking the level of education and experience of the GTAs into account, there is no doubt that the situation is contributing to a compromised quality of tertiary education, especially when the GTAs are teaching senior students and more specialized courses in the undergraduate programs.

The disproportionate number of juniors to senior faculty members coupled with the apparent lack of coordination, lack of teamwork among the senior faculty members, the good will from the seniors, the initiatives from the juniors and lack of incentives for national academic staff were viewed as the major limitations to establish sound senior-junior faculty mentorship. The IHE in Eritrea are struggling with few national senior faculty, large number of expatriates and GTAs. Large number of inexperienced GTAs are holding key responsibilities and eagerly looking for professional mentoring. Unfortunately, the GTA participants were not positively influenced; the GTAs do not want to emulate their seniors. The IHE have huge responsibility to mentor the GTAs to build their competence and professional attitude in order to assume more responsibilities, to live up to the expectations of the colleges is an essential homework of the IHE so that the colleges can stand on their own feet and minimize mass hiring of expatriate instructors on a contractual basis. Through well organized induction and mentorship programs, it might be difficult but not impossible to work with GTAs to change any threat into an opportunity in the Eritrean IHE.

\section{References}

Adams, K. A. (2002). What colleges and universities want in new faculty: Association of American Colleges and Universities.

African Development Fund project (February, 2010 Appraisal Team). Support to higher education development: Eritrea project appraisal report.

Boyden, K. M. (2000). Development of new faculty in higher education. Journal of Professional Nursing, 16 (2), $104-111$

Bozeman, B. \& Feeney, M. K. (2007).Toward a useful theory of mentoring: A conceptual analysis and critique. Administration \& Society, 39 (6), 719-739.

Brown, M. C., Davis, G. L. \& McClendon, S. A. (1999). Mentoring graduate students of color: Myths, models 
and modes. Peabody Journal of Education, 74 (2), 105-118.

Christensen, M. K. (2007). Supervisor/subordinate disconnect: An analysis of URT organization research regarding employee information acquisition (Thesis in communication studies). Texas Tech University.

Ehrich, L. C., Hansford, B. \&Tennent, L. (2001). Closing the divide: Theory and practice in mentoring. Paper for ANZAM 2001 Conference, 'Closing the Divide', Auckland, New Zealand, 5-7 December 2001.

Francis, P. H. (2006). Reconstructing Alma matter: The coming crisis in higher education a blueprint for reform. New York: Algora publishing.

Fuller, K., Maniscalco-Feichtl, M., \& Droege, M. (2008).The role of the mentor in retaining junior pharmacy faculty members. American Journal of Pharmaceutical Education, 72 (2), 1-5.

Hardwick, S. W. (2005). Mentoring early career faculty in geography: Issues and strategies. The Professional Geographer, 57 (1), 21-27.

Hargreaves, A. \& Fullan, M. (2000). Mentoring in the new millennium. Theory into Practice, 39 (1), p. 50-56.

Kanuka, H. (2005). Does mentoring new faculty make a difference? Society for Teaching and Learning in Higher Education, 39. Retrieved from http:/stlhe.ca/ n/publications/newletters/STLHE Newsletter 392005 Winter.pdf.

Kinjerski, V. and Skrypnek, B. J. (2006). Human ecological model of spirit at work. Leadership and organizational development journal, 27 (4): p. $280-295$.

Kosoko-Lasaki, O., Sonnino, R. E., \&Voytko, M. L. (2006). Mentoring for women and underrepresented minority faculty and students: Experience at two institutions of higher education. Journal of the National Medical Association, 98(9), 1449-1459.

Mason, C., (2005). "Briefing session for mentor and mentees: Mentoring - theory and practice.

Mcdevitt, R. (2007). Confucianism understanding and applying the analects of Confucius.Education About Asia, 12(1): 46-47.

McKimm J., Jollie, C. \& Hatter, M. (2007). Mentoring: Theory and practice. Retrieved from http://www.faculty.londondeanery.ac.uk/learning/eedback/files/entorin Theory and Practic e.pdf.

National Board for Higher Education, Eritrea (NBHE). (January, 2010). Higher Education Guidelines. Asmara, Eritrea.

National Board for Higher Education, Eritrea (NBHE). (2010/2011 Academic Year). Statistical Report: Semester I. Asmara, Eritrea

Nickelson, C. W. (2009). Mentoring women graduate students: A model for professional psychology. Professional Psychology: Research and Practice, 40 (3), 284-291.

Park, C. \& Ramos, M. (2002). The donkey in the department? Insights into the graduate teaching assistant experience in the UK. Journal of Graduate Education, 3, 47-53.

Petryk, M. W. P. (2000).Department of chemistry and biochemistry teaching assistants handbook. University of Guelph, Ontario, Canada.

Price, J. \&Cotten, S. R. (2006). Teaching, research, and service: Expectations of assistant professors. The American Sociologist, 37(1), 5-21.

Sundli, L. (2007). Mentoring a new mantra for education? Teaching and Teacher Education, 23, 201-214.

Thorndyke, L. E., Gusic, M. E., George, J. H., Quillen, D. A. \& Milner, R. J. (2006) Empowering junior faculty: Penn State's faculty development and mentoring program. Academic Medicine, 81 (7), 668- 673.

Trask, B. S., Marotz-Baden, R. \& Settles, B. (2009). Enhancing graduate education: Promoting a scholarship of teaching and learning through mentoring. International Journal of Teaching and Learning in Higher Education, 3 (3), 438-446.

Wunsch, M. A. (1993). Mentoring probationary women academics: A pilot program for career development. Studies in Higher Education, 18 (3), 349-362. 